\title{
The Effect of Deliberative Discussion Teaching Strategy on Nursing Students' Learning Motivation
}

\author{
Azza Fathy Ibrahim \\ Nursing Education Department, Faculty of Nursing, Alexandria University. Egypt
}

\begin{abstract}
Deliberative discussion is an important active teaching strategy that encourages learners to participate and share in their learning decisions. Nursing students need lifelong motivation for learning. Therefore, this experimental study was done to determine the effect of deliberative discussion as a teaching strategy on nursing students' learning motivation. The study was conducted at the Faculty of Nursing, Alexandria University, Egypt. The sample included all master degree nursing students $(n=67)$. A strategy for Learning Scale (MSLS) was used to collect the necessary data. The results showed that there was a statistically significance difference in MSLS scores among both study groups, in favor of deliberative group, in all scale items. Conclusion: The use of deliberative discussions can produce an excellent effect on the learning motivation of master nursing students. Further, the deliberative dialogue provides a noted improvement in the interests of graduate nursing students. Recommendations: nursing educators have to develop awareness of the usefulness of deliberative discussions as an effective teaching strategy to enhance learning motivation among nursing students. Repeating the current study using other variables with deliberation such as critical thinking, problem solving and leadership, is suggested. Further research is also needed for a larger number of subjects, as well as a longer period of study time to confirm the effect of deliberation on students' learning process.
\end{abstract}

KEYWORDS: Deliberative, discussion, learning motivation.

\section{Introduction}

Nursing education has a responsibility to prepare and develop nursing curriculums in order to build students' abilities and talents for the 21st century challenges (American Association of Colleges of Nursing, 2008). Nurses are now required to provide professional, safe, skillful and multidimensional care in varied and often unfamiliar settings. Therefore, they should be ready to be competent, intuitive and intelligent clinicians where new information and clinical situations are constantly changing (Thornhill and Wafer, 1997).

It is a challenge for a nurse educator to create innovative paradigms in nursing pedagogy which enhance students' creativity, capabilities and motivation (Melrose, 2004). How can the nurse educator enhance nursing students' learning motivation? It is a very important question that requires understanding of the students' situation and need for tutorial support (Nilsson and Stomberg, 2008).

\section{Review of the Literature}

Student learning is complicated and wide ranging, especially when talking about instruction in nursing education (Ryan and Deci, 2000). For more effectiveness and success in the learning process, one must be willing and motivated to learn. This is especially true for graduate students who should have the motivation to be ready and competent in problem solving, decision making, and using professional judgment. Curricula grew long on what, when, where, and how to, but short on the why and whether elements (Cowman, 1998; Facione et al., 1997). Learning occurs under the umbrella of motivation as explained by educational psychology and learning theories.

Behaviorism focuses on positive consequences increasing the behavior's probability while negative consequences decrease it (Skinner, 1953). The educator has a major role in organizing the learning environment to ensure that correct and desired behaviors are likely to occur, and that when it does, students will be rewarded. Incorrect responses are either punished or ignored (Svinicki, 2003). As regards a cognitive approach, learning is a structuring and restructuring of memory. Information is coming from the environment and then received by the learner's attention as a result of entered consciousness. The educator should be the director of the informational processing. When educators think out loud while solving problems in front of learners, this helps them to imitate, be aware and motivated. Awareness, understanding and recognition are major elements that enhance selfconfidence and motivation to learn (Chi et al, 1994 and Pintrich, 2003).

A constructivist approach emphasizes the degree to which the learners are constructing their own view of the world. The learner creates his/her own learning construct that is consistent with past experiences and present situations. This view focuses on personal responsibility about one's own learning. Therefore, educators tend to pay more attention to activate the role 


\section{Azza Fathy Ibrahim" The Effect of Deliberative Discussion ..."}

and self-regulation of learners which is based on their motivational value (Facione et al., 1997 and Ormrod, 1999). Moreover, a humanistic view describes that the individual's mind is strongly influenced by ongoing determining forces in both the unconscious and the surrounding world, specifically by the society in which he/she lives. Learning occurs when a person's attitudes and feelings are changed. This depends on intrinsic feelings, self-initiation, self-awareness, personal development, autonomy (self-control), selfactualization, self-determination, self-confidence, selfconcept and motivation. Therefore, educators should create a learning environment that motivates learners by using different teaching strategies and encouraging their autonomy and self-awareness about their own learning. Many researches highlight the importance of learning motivation as a predictor for academic success in higher education (Ormrod, 1999 and Ryan and Deci, 2000). It was observed that motivation is an essential part of all learning theories. Therefore, educators must know more about the process of learning motivation and suggest ways to support it.

Motivation is a goal that directs the human behavior most closely linked to feelings of personal effectiveness. To be motivated means to be eager to do something. Motivation in education can have several effects on students learning and how they behave towards their learning (Ormrod, 1999 and Pintrich, 2003).

The Self-Determination Theory (SDT) distinguishes among types of learning motivation based on the different goals to do a certain action. 1. Intrinsic motivation; which refers to doing something because it is inherently interesting or enjoyable. 2. Extrinsic motivation; which refers to doing something because it leads to a separable outcome or surrounding benefits ( Ryan and Deci, 2000). There are various forms of extrinsic motivation such as external regulation, introjected regulation, identified regulation, and integrated regulation. These types vary in the degree of self-determination that is associated with the behavior. More internalized or more integrated behaviors produce a greater sense of self-determination. Thus, as one moves along the extrinsic continuum (from external to integrated), motivation begins to take on more and more characteristics associated with intrinsic motivation (Fairchild et al., 2005).

Therefore, what must the nurse educator know about learning? How to make it easy for learners? They have to tailor their teaching strategies in order to meet the demands of a new health care system, motivate students to develop critical thinking skills and encourage problem-solving abilities through active learning strategies (O'Shea, 2003).

Students' learning motivation and teaching strategies are interrelated and have one goal which is to improve the students' chances of success. Educators who understand student motivation can greatly enhance the classroom experience and student performance. Incorporating active teaching methods with students allows for greater student interaction and the opportunity for students to practice newly acquired skills and knowledge. Supplementing teaching sessions with guest panels, discussion, case study or student presentations can break the monotony, minimize passive observation and increase students' motivation (Oermann, 2004).

Discussion is an excellent strategy for enhancing student learning motivation, fostering intellectual agility and encouraging democratic habits. It is diverging from the norm, which can help students learn more than what they usually are capable of by drawing their interest. It creates opportunities for students to practice and sharpen a number of skills, including the ability to articulate and defend positions, consider different points of view and enlist and evaluate evidences (Brookfield and Preskill, 1999). While a variety of discussion methods exist, relatively unknown to nursing is the deliberative discussion which is a method of teaching that was developed by the National Issues Forums Institute for the sole purpose of creating a means to engage people to dialogue with one another (Goodin and Stein, 2009).

The process of deliberation was described according to Brookfield and Preskill in 1999, "Deliberation refers to the willingness of participants to discuss issues as fully as possible by offering arguments and counterarguments that are supported by evidence, data, and logic and by holding strongly to these unless there are good reasons not to do so." The deliberative discussion is a purposeful and serious discourse that does not rush to a decision but rather towards careful consideration of alternative points of views and choices.

In deliberative discussion technique, the educator is a moderator who is an individual familiar with the national forum to guide the participants through the dialogue. Then, the educator establishes ground rules to manage the dialogue of each learner and introduces the topic that is the focus of the deliberative discussion. Because the learners rarely read prior to the teaching session, the educator provides a brief summary about the issue by presentation, reading or by showing a 10 minute videotape. The educator connects the issue to the participants' lives by inviting them to take a personal stake. Participants are given the opportunity to share their personal experiences with the issue which helps to make the issue real and pertinent. At the heart of deliberation, nursing students have a willingness to work through the conflicts, to accept the consequences of their choices, and to establish grounds for action (Goodin and Stein 2008; Goodin and Stein, 2009 and Mello, 2010).

Nurse educators must construct a learning environment that will provide learners with the opportunity to question scrutinize, challenge assumptions and rate all the points of view offered to challenge and motivate their thinking. So, deliberative discussion is a teaching method which can be applied in the course of "Ideology, Ethics and Basic Law" that can inspire students' initiatives and focus on their abilities. It abandons the traditional teaching mode, thus making the class vivid, interesting, motivating, comprehensive and profound (Goodin and Stein, 2008 and YU Linping, 2009). 


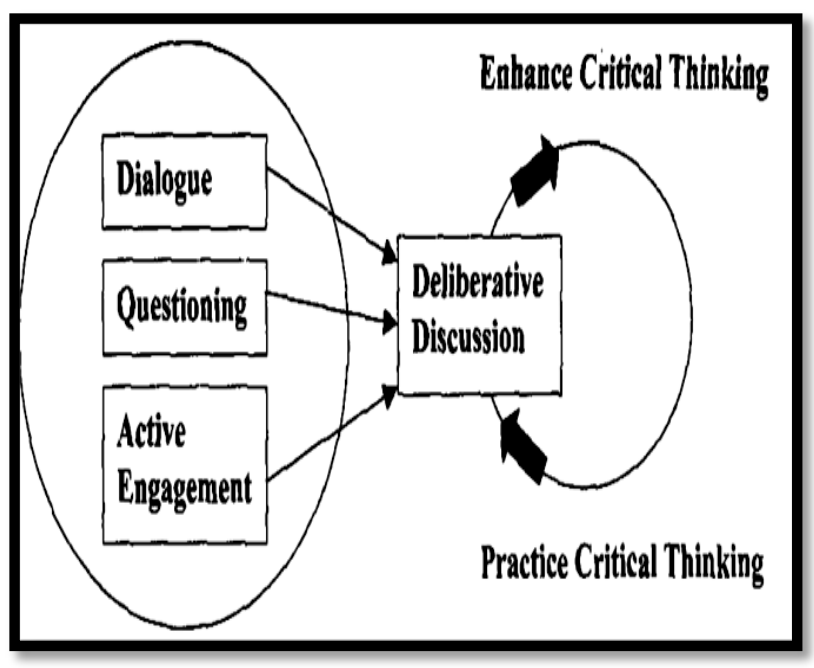

Figure I. Conceptual Framework. The practices ofdialogue, questioning, and active engagement ( in Goodin H., Stein D. The Use of Deliberative Discussion to Enhance the Critical Thinking Abilities of Nursing Students. The Berkeley Electronic Press, 2009. 5 (1) 5).

Figure I., illustrates that dialogue, questioning, and active engagement are the essential elements of a successful deliberative discussion. When nursing students are interested and motivated to learn nursing sciences, they will be active learners and their learning retention will be increased. Consequently, this will be reflected in their nursing profession. Nursing is a humanistic profession that requires a student who has loyalty, empowerment, self-confidence, self-efficacy and motivation towards his/her career (Goodin and Stein, 2008 and YU Lin-ping, 2009). Perhaps more important, graduate nursing students with professional degrees are better prepared to lead deliberative processes in their professional realm of responsibility.

The purpose of this study is to assess the effect of deliberative discussion as a teaching strategy on nursing students' learning motivation.

Hypotheses: Nursing students who have been instructed through deliberative discussion teaching strategy will have higher learning motivation than those who have been instructed through traditional teaching methods.

A quasi-experimental design was utilized to accomplish this study at the Faculty of Nursing, University of Alexandria.

The study sample included all master nursing students (67) enrolled in the 1st semester in the Health Education elective course in the academic year of 2011-2012. A convenient sample included sixty of the master nursing students who agreed to participate in the study. They were divided randomly into two groups:

Study group: thirty master nursing students who were instructed about ethical principles and the code of ethics in health education using deliberative discussion teaching strategy.
Control group: thirty master nursing students who were instructed about ethical principles and the code of ethics in health education using a traditional teaching strategy.

Study instrument: Motivated Strategies for Learning Scale (MSLS) was used in data collection, which was developed by Pintrich et al., in 1991 to assess college students' learning motivational orientations during teaching-learning activities and revised by Somtsewu N., in 2008. It included eighty one items. Each item was followed by a seven point Likert Scale ranging from not at all true (1) to very true (7). A reversed scoring was allotted to negative statements. It contained two sections:

Section 1: Learning motivation: It consisted of thirty one items that assessed students' goals, value beliefs towards a course, belief about the ability to succeed in a course and anxiety about tests. This section included assessment of three general motivation constructs, in terms of: 1- Expectancy, included students' beliefs that they expected to accomplish a task. That was assessed major two expectancy components: Control of Learning Beliefs and the Self-Efficacy for Learning and Performance. 2- Value: referred to the reasons for students' engagement in an academic task. 3-Affect: denoted to students' concern over taking examinations (anxiety in exams).

Section 2: strategies of learning which consists of fifty items about cognitive and meta-cognitive (the behaviors and thoughts in which students were engaged while studying: Rehearsal, Elaboration, Organization, Critical Thinking, and Meta-cognitive Self-Regulation) and resource management learning strategies (how the students manage and regulate their time and study environments, monitor effects, learn from peers and seek help and support from peers and educators' socio demographic characteristics were included as well).

Scoring system: A seven point rating likert scale was used by students and responses scored from "not at all true of me" to "very true of me." Scales are constructed by taking the mean of the items that make up that scale. i.e. intrinsic goal orientation having four items. An individual's score for intrinsic goal orientation would be computed by summing the four items and taking the average. Items marked as "reversed" are reverse coded items. These negatively worded items and the ratings have to be reversed before an individual's score can be computed. If an item has to be reversed, a person who has circled 1 for that item now receives a score of 7 and so on. Accordingly, a 1 becomes a 7, a 2 becomes a 6 , a 3 becomes a 5 , a 4 remains a 4 , a 5 becomes a 3 , a 6 becomes a 2, and a 7 becomes a 1 . The simplest way to reflect a reverse coded item is to subtract the original score from 8 . i.e., if the original score was 2 to the negatively worded item, one would compute 8-2 = 6 ; 6 being the score for the positively worded version of that question.

Method: 


\section{Azza Fathy Ibrahim" The Effect of Deliberative Discussion ..."}

* An official approval was obtained from the ethical committee, responsible authorities and participants after explaining the aim of the study.

* The study tool was modified after a thorough review of related literature (Pintrich, 1991; Pintrich et al., 2003 and Somtsewu, 2008). It was tested for content validity by five experts in nursing education and nursing administration fields and consequently, necessary modifications were done. Then it was statistically tested for reliability by the Cronbach Alpha Coefficient Statistical Test that revealed reliability in between (0.74 to 0.86$)$.

* A pilot study was done using a study tool on seven master nursing students in another elective course that was apart from study subjects. Applicability,

3) The sessions of the deliberative discussion were held in the morning from 9:00 AM to approximately $11.00 \mathrm{AM}$. The control group took their sessions in the morning from 11:00 AM to approximately 1.00 PM., on Mondays for three weeks.

4) The researcher prepared three deliberative discussion sessions about health education ethical principles and its code of ethics based on a thorough review of related literature to be taught to study group. While, control group was taught by traditional method of teaching. Both groups were asked to read carefully and prepare this unit a week before.

5) In deliberative discussion session, the researcher acted as a moderator, then arranged the class and seats to permit face-to-face conversation between master nursing students.

- The rules of the session, organization of students - teacher's role - students' interactions, purpose and the topic of the deliberation sessions were explained.

- The researcher provided a brief summary about the topic by storytelling and reading. This was tied the issue with the students' life and work and the researcher discuss their personal experiences related to the topic.

- At the beginning of each session, the researcher asked four questions to stimulate their thinking, in-terms of: What is the importance of the presented topic in the health education field?, What are the benefits and risks for that topic?, Where are the conflicts that the students have to work through to reach a conclusion?, and, Can the students detect any shared sense of direction or common ground for utilization of the topic in health education with patients?

6) Each student wrote the answers and the reflection of the topic in their lives and work. Students shared their comments and work experiences with each other and they followed the time settled by the moderator. They discussed ethical principles subtitles of health education: confidentiality, justice, autonomy, mal-efficiency, veracity, fidelity. Each student discussed her/his topic for 10 minutes.

7) The moderator remained neutral while guiding students through the process and encouraged them clarity and necessary modifications were done accordingly.

The following were the steps that followed in implementation of the deliberative teaching method:

1) Both study groups received the study tool and completed it in the presence of the researcher to help them understand its statements.

2) The deliberative discussion sessions were conducted in the same classroom that scheduled for master nursing students. The researcher arranged with the control group to take their sessions in the same class immediately after the study group.

to weigh all the alternatives for each subtitle of the topic.

8) Students were encouraged to connect discussed points with values, ideas, personal stories. Also, they were asked to provide examples, and to explore the consequences of actions on different patient situations.

9) The researcher controlled and guided discussions between students and provided feedback after each subtitle.

10) Students were asked to write down their comments and ideas related to each session subtitle, and at the end of each session, the moderator asked for feedback and then provided a brief summary and conclusion.

11) Students were asked to provide recommendations. The moderator asked the students some questions in this step to elicit their reflection about the deliberation topic, such as: How has your thinking about the issue changed?, How can we use what has been learned in a nursing career?, and what do we want to do next?

12) Students' comments were gathered and analyzed to explore their reflection and check purposes and accomplishments.

13) Immediately after the deliberative sessions, both study groups received the study tool and completed it to reassess their learning motivation regarding both types of instruction in the presence of the researcher in order to help them understand its statements.

14) In posttest, the nursing students in the study and controlled groups were reassessed using study tool, in the presence of the researcher. 


\section{Results:}

Statistical Packages for the Social Sciences (SPSS) version 15.0 for Windows and Microsoft Excel Spread sheet package (Office 2007) were used in data analysis. Mean and standard deviation as well as Chi square, and $\mathrm{T}$ test with $\mathrm{P}$ value for was applied for descriptive data and comparisons between the study groups. In addition, the Effect size test was used.

Table 1: showed the characteristics for the study and the control groups. Approximately, all participants had bachelor degrees. There was not a statistically significant difference between both groups; related to sex, age and job, at 5\% level of statistical significance.

Table I: Description of the study sample

\begin{tabular}{|c|c|c|c|c|c|c|c|c|c|c|c|c|c|c|c|c|c|c|c|}
\hline \multirow{3}{*}{$\stackrel{0}{\tilde{0}}$} & \multirow{3}{*}{ 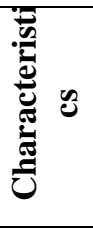 } & \multicolumn{4}{|c|}{ Sex } & \multicolumn{6}{|c|}{ Age } & \multicolumn{8}{|c|}{ Current job } \\
\hline & & \multicolumn{2}{|c|}{ Female } & \multicolumn{2}{|c|}{ Male } & \multicolumn{2}{|c|}{$\begin{array}{c}20 \leq 25 \\
\text { years }\end{array}$} & \multicolumn{2}{|c|}{$\begin{array}{c}26 \leq 30 \\
\text { years }\end{array}$} & \multicolumn{2}{|c|}{$\begin{array}{c}\mathbf{3 0} \leq \mathbf{3 5} \\
\text { years }\end{array}$} & \multicolumn{2}{|c|}{ Demonstrator } & \multicolumn{2}{|c|}{$\begin{array}{c}\text { Clinical } \\
\text { instructor }\end{array}$} & \multicolumn{2}{|c|}{$\begin{array}{l}\text { Registered } \\
\text { nurse }\end{array}$} & \multicolumn{2}{|c|}{ Preceptor } \\
\hline & & No & $\%$ & No & $\%$ & No & $\%$ & No & $\%$ & No & $\%$ & No & $\%$ & No & $\%$ & No & $\%$ & No & $\%$ \\
\hline 包 & 30 & 27 & 90 & 3 & 10 & 21 & 70 & 3 & 10 & 6 & 20 & 8 & 26.7 & 10 & 33.3 & 6 & 20 & 6 & 20 \\
\hline है & 30 & 29 & 96.7 & 1 & 3,3 & 18 & 60 & 5 & 16.7 & 7 & 23.3 & 9 & 30 & 12 & 40 & 3 & 10 & 6 & 20 \\
\hline & $X^{2}$ & & 1.0 & & & & & & 024 & & & & & & & & & & \\
\hline
\end{tabular}

$\mathbf{X}^{2}=$ Chi square test (used to detect the difference among two or more percentages) P: level of significant $<0.05$

Table 2: illustrated that, before the educational interventions there was no a statistical significant difference between study and control groups. But after implementing the educational interventions, there was a statistical significant difference between the two groups, the deliberative group had higher value components than control group. There were stronger effect sizes for the study group than the control group for all elements of value components. Effect size for study group $=1.6$, 1.5, 1.4 VS Effect size for control group $=0.7$, $0.6,0.05)$.

Table 2: Comparing between study and control groups in relation to value components.

\begin{tabular}{|c|c|c|c|c|c|c|c|c|c|c|c|c|}
\hline \multirow{3}{*}{$\begin{array}{c}\text { Value } \\
\text { components }\end{array}$} & \multicolumn{5}{|c|}{ Study group $(\mathrm{N}=30)$} & \multirow{3}{*}{$\begin{array}{c}\text { Effectsi } \\
\text { ze }\end{array}$} & \multicolumn{5}{|c|}{ Control group $(\mathrm{N}=30)$} & \multirow{3}{*}{$\begin{array}{c}\text { Effect } \\
\text { size }\end{array}$} \\
\hline & \multicolumn{2}{|c|}{ Before } & \multicolumn{2}{|c|}{ After } & \multirow{2}{*}{ T test } & & \multicolumn{2}{|c|}{ Before } & \multicolumn{2}{|c|}{ After } & \multirow{2}{*}{ T test } & \\
\hline & $\overline{\mathbf{X}}$ & SD & $\overline{\mathbf{X}}$ & SD & & & $\overline{\mathbf{X}}$ & SD & $\overline{\mathbf{X}}$ & SD & & \\
\hline $\begin{array}{c}\text { Intrinsic goal } \\
\text { orientation }\end{array}$ & 14.87 & 2.70 & 18.10 & 3.73 & 8.73 & 1.594 & 13.57 & 3.21 & 15.07 & 2.95 & 3.67 & 0.670 \\
\hline $\begin{array}{l}\text { Extrinsic goal } \\
\text { orientation }\end{array}$ & 13.57 & 3.79 & 16.73 & 2.79 & 8.00 & 1.461 & 12.60 & 2.76 & 13.70 & 2.39 & 3.11 & 0.568 \\
\hline Task value & 18.57 & 3.84 & 22.37 & 3.57 & 7.87 & 1.437 & 17.00 & 3.33 & 17.20 & 3.81 & 0.25 & 0.045 \\
\hline
\end{tabular}

P: level of significant relation $\leq 0.01$, Degree of freedom $=58$, Effect size test $=$ indicates to which extent the intervention is effective.

$* *=0.5 \leq 0.8$ moderate effect

$\underline{\text { Table } 3}$ illustrated that there was a statistical significant difference between the control and the study group after the educational interventions, Therefore, the master nursing students in the study group better expectancy components than students in the control group. Therefore, they had

$$
*=0.2 \leq 0.5 \text { weak effect }
$$

$$
* * *=0.8 \leq 1 \text { strong effect }
$$

better Effect size $=1.5$ for study group VS. 0.22 for control group, in controlling learning beliefs. And for self-efficacy for learning and performance, Effect size for study group = 1.7 VS. 0.5 for control group, an

$$
\mathrm{d} \mathrm{P} \leq 0.01 \text {. }
$$


Table III: Comparing between study and control groups in relation to expectancy components.

\begin{tabular}{|c|c|c|c|c|c|c|c|c|c|c|c|c|}
\hline \multirow{3}{*}{$\begin{array}{l}\text { Expectancy } \\
\text { components }\end{array}$} & \multicolumn{5}{|c|}{ Study group $(\mathrm{N}=30)$} & \multirow{3}{*}{$\begin{array}{c}\text { Effect } \\
\text { size }\end{array}$} & \multicolumn{5}{|c|}{ Control group ( $\mathbf{N = 3 0}$ ) } & \multirow{3}{*}{$\begin{array}{c}\text { Effect } \\
\text { size }\end{array}$} \\
\hline & \multicolumn{2}{|c|}{ Before } & \multicolumn{2}{|c|}{ After } & \multirow{2}{*}{ T test } & & \multicolumn{2}{|c|}{ Before } & \multicolumn{2}{|c|}{ After } & \multirow{2}{*}{$T$ test } & \\
\hline & $\overline{\mathbf{X}}$ & SD & $\overline{\mathbf{X}}$ & SD & & & $\overline{\mathbf{X}}$ & SD & $\overline{\mathbf{X}}$ & SD & & \\
\hline $\begin{array}{c}\text { Control of learning } \\
\text { beliefs }\end{array}$ & 14.07 & 2.53 & 18.83 & 4.15 & 8.10 & 1.479 & 14.60 & 3.42 & 15.53 & 3.32 & 1.22 & 0.222 \\
\hline $\begin{array}{l}\text { Self-efficacy for } \\
\text { learning and } \\
\text { performance }\end{array}$ & 31.93 & 7.44 & 40.70 & 8.22 & 9.19 & 1.678 & 31.23 & 7.34 & 32.23 & 7.61 & 2.79 & 0.509 \\
\hline
\end{tabular}

P: level of significant relation $\leq 0.01$, Degree of freedom $=58$, Effect size test $=$ indicates to which extent the intervention is effective. $\quad *=0.2 \leq 0.5$ weak effect $\quad * *=0.5 \leq 0.8$ moderate effect

$* * *=0.8 \leq 1$ strong effect

Table 4, It was clear that, students in study group had higher anxiety test score means, than students in the control group. Therefore, the study group had a strong effect size in affective components than control group, Effect size $=1.7$ VS. 0.7.

Table 4: Comparing between study and control groups in relation to affective expectancy.

\begin{tabular}{|c|c|c|c|c|c|c|c|c|c|c|c|c|}
\hline \multirow{3}{*}{$\begin{array}{l}\text { Affective } \\
\text { components }\end{array}$} & \multicolumn{5}{|c|}{ Study group $(\mathrm{N}=30)$} & \multirow{3}{*}{$\begin{array}{c}\text { Effect } \\
\text { size }\end{array}$} & \multicolumn{5}{|c|}{ Control group $(\mathrm{N}=30)$} & \multirow{3}{*}{$\begin{array}{c}\text { Effect } \\
\text { size }\end{array}$} \\
\hline & \multicolumn{2}{|c|}{ Before } & \multicolumn{2}{|c|}{ After } & \multirow{2}{*}{ T test } & & \multicolumn{2}{|c|}{ Before } & \multicolumn{2}{|c|}{ After } & \multirow{2}{*}{ T test } & \\
\hline & $\overline{\mathbf{X}}$ & SD & $\overline{\mathbf{X}}$ & SD & & & $\overline{\mathbf{X}}$ & SD & $\overline{\mathbf{X}}$ & SD & & \\
\hline Anxiety & 19.8 & 3.58 & 24.3 & 3.73 & 9.35 & 1.71 & 18.6 & 3.22 & 20.47 & 4.07 & 3.958 & 0.723 \\
\hline
\end{tabular}

P: level of significant relation $\leq 0.01$, Degree of freedom $=58$, Effect size test $=$ indicate to which extent the intervention is effective. $\quad *=0.2 \leq 0.5$ weak effect $\quad * *=0.5 \leq 0.8$ moderate effect

$* * *=0.8 \leq 1$ Strong effect

The findings in Table $\mathbf{5}$ showed that the students in the study group had better mean scores after the educational intervention in all items related to cognitive and meta-cognitive learning strategies apparently (elaboration, critical thinking, peer learning and help
Seeking strategies, etc..) Than the control group. Therefore, they had a stronger effect size than the students in the control group. For this reason, there was statistical significant difference at $5 \%$ level of significance.

Table 5: Comparing between study and control groups in relation to cognitive and meta-cognitive learning strategies.

\begin{tabular}{|c|c|c|c|c|c|c|c|c|c|c|c|c|}
\hline \multirow{3}{*}{$\begin{array}{c}\text { Cognitive and } \\
\text { meta- cognitive } \\
\text { learning strategies }\end{array}$} & \multicolumn{5}{|c|}{ Study group $(\mathbf{N}=30)$} & \multirow{3}{*}{$\begin{array}{l}\text { Effect } \\
\text { size }\end{array}$} & \multicolumn{5}{|c|}{ Control group $(\mathrm{N}=30)$} & \multirow{3}{*}{$\begin{array}{c}\text { Effect } \\
\text { size }\end{array}$} \\
\hline & \multicolumn{2}{|c|}{ Before } & \multicolumn{2}{|c|}{ After } & \multirow{2}{*}{$\begin{array}{l}T \\
\text { test }\end{array}$} & & \multicolumn{2}{|c|}{ Before } & \multicolumn{2}{|c|}{ After } & \multirow{2}{*}{ T test } & \\
\hline & $\overline{\mathbf{X}}$ & SD & $\overline{\mathbf{X}}$ & SD & & & $\overline{\mathbf{X}}$ & SD & $\overline{\mathbf{X}}$ & SD & & \\
\hline Rehearsal & 12.77 & 1.88 & 16.47 & 2.16 & 9.48 & 1.732 & 13.07 & 2.132 & 14.033 & 2.059 & 2.81 & 0.513 \\
\hline
\end{tabular}


Azza Fathy Ibrahim" The Effect of Deliberative Discussion ..."

\begin{tabular}{|c|c|c|c|c|c|c|c|c|c|c|c|c|}
\hline Elaboration & 20.13 & 4.29 & 25.83 & 5.05 & 7.91 & $\mathbf{1 . 4 4 3}$ & 18.43 & 3.15 & 21.10 & 4.59 & 3.64 & $\mathbf{0 . 6 6 5}$ \\
\hline Organization & 14.73 & 1.98 & 17.67 & 3.04 & 6.76 & $\mathbf{1 . 2 3 4}$ & 15.27 & 2.08 & 15.57 & 3.51 & 0.38 & $\mathbf{0 . 0 7 0}$ \\
\hline Critical Thinking & 17.23 & 2.01 & 20.97 & 3.10 & 7.46 & $\mathbf{1 . 3 6 2}$ & 17.90 & 3.80 & 18.37 & 4.02 & 0.41 & $\mathbf{0 . 0 7 5}$ \\
\hline $\begin{array}{c}\text { Meta-cognitive self } \\
\text { regulation }\end{array}$ & 43.13 & 7.98 & 52.13 & 8.92 & 6.94 & $\mathbf{1 . 2 6 7}$ & 43.83 & 7.74 & 43.20 & 5.88 & -0.35 & $\mathbf{- 0 . 0 6 4}$ \\
\hline $\begin{array}{c}\text { Time and study } \\
\text { environment }\end{array}$ & 14.60 & 3.42 & 15.53 & 3.32 & 1.22 & $\mathbf{0 . 2 2 2}$ & 28.23 & 5.92 & 29.93 & 5.77 & 1.02 & $\mathbf{0 . 1 8 6}$ \\
\hline Peer learning & 8.87 & 2.68 & 13.53 & 2.87 & 9.82 & $\mathbf{1 . 7 9 2}$ & 8.57 & 1.81 & 10.57 & 3.43 & 2.57 & $\mathbf{0 . 4 6 9}$ \\
\hline Help seeking & 12.53 & 3.28 & 15.80 & 4.17 & 7.27 & $\mathbf{1 . 3 2 7}$ & 12.13 & 2.86 & 11.83 & 2.71 & -0.41 & $\mathbf{- 0 . 0 7 5}$ \\
\hline
\end{tabular}

Significant relation at $\mathrm{P}$ level $<0.05$, Effect size test (among $\overline{\mathrm{X}}$ after intervention) $=$ indicates to which extent the intervention is effective. $*=0.2 \leq 0.5$ weak effect $* *=0.5 \leq 0.8$ moderate effect $\quad * * *=0.8 \leq 1$ strong effect

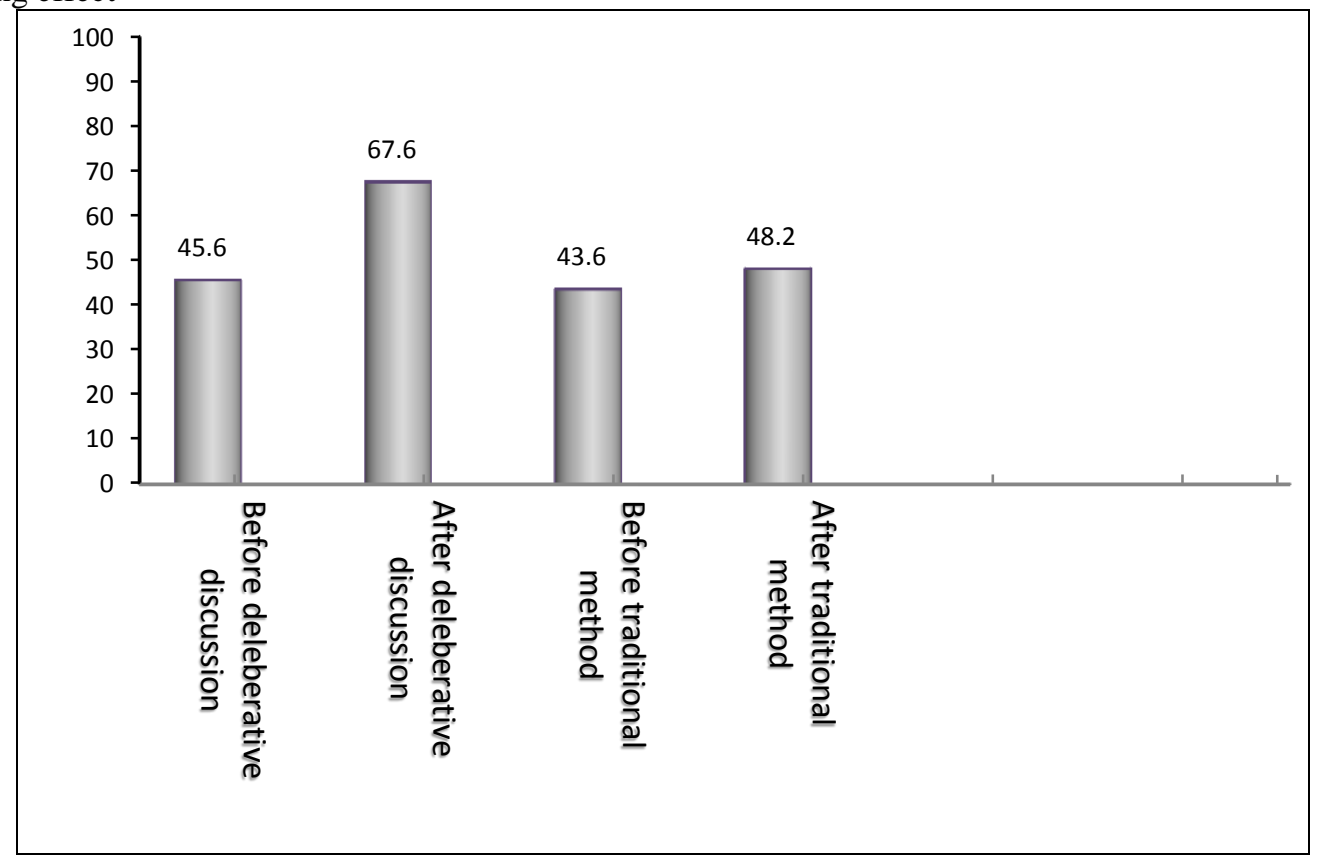

Figure 1: Mean percent of master nursing student's MSLQ scores before and after the educational interventions.

\section{Discussion}

The concept of motivation and the strategies of learning that a student uses have an effect on the individual's ability to progress through nursing academic achievement. The drive to prepare, the ability to utilize effective study habits, and existing anxieties all influence the student's performance (Carpenter, 2010, Somtsewu, 2008).

The current study hypnotized that there are multiple reasons that determine why learning motivation changes as a result of the teaching approaches such as challenge, curiosity and mastery.

Responses of students in study group, after the educational interventions, were better than the control group in relation to intrinsic, extrinsic goal orientation and task value. This proved that the deliberative approach which encouraged the internal goal motivation to learn besides increasing the awareness of the students about the value and usefulness of the achieved task was successful. Importance or attainment for task value and referred to how to appreciate the importance of the task to do well, as well as how central the task was perceived to be to the individual's personal identity. Therefore, the innovative strategies which included the provision of tasks and activities that were interesting, stimulating, novel, and personally meaningful in some manner, were helped to increase intrinsic, extrinsic goal orientation and task value (Ford, 2003 Somtsewu, 2008).

As revealed in the current results, the study group gained high scores regarding extrinsic goal orientation which could be numerous such as; grades, competition with peers, social goals, academic achievement and evaluation of others. Therefore, the variety of extrinsic 
goals tended to limit and decrease the effect of teaching methods more than other components of learning motivation. But deliberation discussion increased the extrinsic goal orientation among the study group. Congruent with this finding, Somtsewu, in 2008 clarified that there were multiple goals that students could pursue in a classroom, and there was a comprehensive taxonomy of twenty four goals that individuals might pursue in any context. The roles of these different goals played an important role in learning, adjustment, and academic achievement. Moreover, during teaching sessions with both groups, the master nursing students frequently said that they had several roles, duties and responsibilities than any other students. Adult students frequently studied and maintained a job which is considered a great burden and might lead to frustration.

For task value, the deliberative discussion tended to enhance master students' perception of the course material in terms of interest, importance and the utility of a course. This was in line with those who emphasized that high task value scores had been associated with increased involvement in learning. When the student was aware of task benefits, this enhanced active participation. (Kivinen, K.2002)

Another finding, in the current study is that there was a statistically significant difference after implementing the educational interventions between the two groups related to the expectancy components of MSLQ, including control of learning beliefs and self-efficacy for learning and performance. This could explain why active participation and student interaction had apparent roles in motivating their learning. If students felt that their efforts would help to accomplish result in accomplish the task, they would have better learning outcomes and self-efficacy (Pintrich, P 2003).

The deliberative discussion approach has a strong effect on relieving anxiety among the study group more than the control group. Without any doubt, motivated and interactive students exhibit less anxiety toward an achievable task. This can be clarified that the deliberation discussion enhances and motivates students' dynamics with minimal interference from the teacher. Therefore, students with deliberation will have limited worry about their ability in learning and beliefs of consequences of answering questions that were provided in deliberation.

Deliberative discussion is a cooperative experience, not a competitive approach. Many students of the deliberative group illustrated that they were invited and interested without anxiety because they discussed life experiences at their work place. They were interested and not worried. There has been little research on the role of affect and emotions in the classroom but nowadays emotions and feelings are great elements of learning and have a direct effect on achieving the cognitive aspect of academic achievement. Affect and inner feelings can enhance the learners to accomplish their goals and lead them to gain different types of information as well as behaviors (Pintrich, 2003 and Nilsson and Stomberg, 2008).

To encourage students' learning motivation and develop independent learning skills and strategies, teachers need to focus and identify students' beliefs, points of views, opinions and values and how these motivational beliefs affect learning (Boekaerts, 2002).

Moreover, deliberation enhances adult students' selfefficacy which is the individuals' confidence in their ability to control their thoughts, feelings and actions and therefore their ability to influence a learning outcome (Bandura, 1989). Master nursing students acquired information to assess self-efficacy beliefs and the extent to which they have confidence to achieve their task.

As regards cognitive and meta-cognitive learning strategies, the study group proved that they were having better learning strategies that enhanced learning motivation during the deliberative sessions than the control group. The moderator during deliberation encouraged graduate students to build their own construct through using their own views in elaboration, critical thinking, peer learning and help seeking learning strategies. This was emphasized by Wernke et al. in 2001 who stated that there were some common assumptions. Strategic action, meta-cognition, and (intrinsic) motivation were important aspects in a learning process which act through self-regulated learning. The activity and dynamics of a learner were essential aspects to the degree that the learner will be meta-cognitively, motivationally, and behaviorally active participants in their own learning process.

Deliberation discussion emphasizes enhancing cognitive activity, democracy sharing and selfregulation. To be a self-regulated learner, one must use specific learning strategies to achieve the academic goals on the basis of self-perception. Such learning methods include goal-setting, planning, organizing and transforming, rehearsing, memorizing, record-keeping and self-monitoring. The use of self-regulating learning strategies in deliberation allows students to use effective information processing (Leung, and Chan, 2002 and Goodin, and Stein, 2008).

Both types of educational interventions had no effect on its implementation as regards time and study environment strategies. This aspect of meta-cognitive strategies may be difficult for current study due to limited time of deliberation sessions as the students took only a unit and not a complete course. In line with this point of view, Pintrich in 1991, discussed that time management involved scheduling a time to study, organizing weeks or months in advance for assignments or exams, and the appropriate use of study time for real and accurate goals, which require a lengthy time for a complete course.

Furthermore, study environment management refers to the ability of students to arrange the physical place of learning which is difficult because the arrangement for deliberation is different than other study courses. So, the deliberation failed to enhance this meta-cognitive 
approach. This is incongruent with Somtsewu, in 2008 who stressed that the arrangement and awareness of physical suitability of the learning place and how to shape it to be a helping aspect in the learning and teaching process, is a strong meta-cognitive approach that is a sign of actively motivating the student.

Deliberative processes are enhancing students' strategy to the way that makes decisions. It involves the students' choice to engage actively in democratic life. It prepares students to become decision-making citizens and motivated learners, ready to participate and interact and have the ability, feelings and thoughts toward cooperation and interaction.

Conclusion

Nursing students who had been instructed by deliberative discussion teaching strategy had higher learning motivation than those who had taught by traditional teaching method. The use of deliberative discussions could produce an excellent effect on the learning motivation of master nursing students.

\section{Recommendations:}

Professional nursing educators must be aware of all teaching strategies that could improve the awareness, feelings and practices of learners through discussions. Collaboration between the academic team and other clinical disciplines are more effective in providing an opportunity to demonstrate the contribution of innovative teaching approaches in nursing. Moreover, the present study provides a view to further studies as follows:

- Repeating the current study using other variables with deliberation such as critical thinking, problem solving and leadership.

- Further research is also needed for a larger number of samples, as well as a longer period of study time to confirm the effect of deliberation on students' learning process.

- Other research can be done about the relation between learning motivation awareness and compliance.

- Another study can be establish for developing an educational program for collaboration, guidance and support for teachers to use active and interactive teaching strategies.

\section{References}

[1] American Association of collages of nursing. (2008) The essentials of Baccalaureate Education for Professional Nursing. USA. Washington, 3-6.

[2] Bandura, A. Human agency in social cognitive theory. (1989) American Psychologist, 44, 1175-1184.

[3] Boekaerts M. ( 2002) Motivation to learn. France, International Academy of Education, available at http://www.curtin.edu.au/curtin/dept/smec/iae retrieved at February 2012

[4] Brookfield, S. Preskill, S. (1999) Discussion as a way of teaching: Tools and techniques for democratic classrooms. San Francisco: Jossey-Bass. in Goodin, H.J. Stein, D. (2008) Deliberative discussion as an innovative teaching strategy. Journal of Nursing

Education, 47(6), 272-274.

[5] Carpenter J. (2010) Locus of control \& Motivation Strategies for Learning Questionnaire: Predictors of Student Success on the ATI Comprehensive Predictor Exam \& NCLEX-RN Examination. Doctoral Thesis, School of Education, University of Kansas, 60-69

[6] Chi, M., Slotta, J., De Leeuw, N. (1994) "From Things to Processes: A Theory of Conceptual Change for Learning Science Concepts." Learning and Instruction, 4, 27-43.

[7] Cowman S. (1998) The approaches to learning of student nurses in the Republic of Ireland and Northern Ireland. 28(4):899-910.

[8] Facione P., Facione N., Giancarlo C. (1997) The Motivation to Think in Working and Learning. San Francisco, CA: Jossey-Bass Publishers. 67-79.

[9] Fairchild A, Horst S., Finney S., Barron K. (2005) Evaluating New and Existing Validity Evidence for the Academic Motivation Scale. Contemporary Educational Psychology, 30, 331 -358.

[10] Ford, M. (2000) Motivating humans: Goals, emotions, and personal agency beliefs. Newbury Park, CA: Sage. In Pintrich, P. R. (2003) A Motivational Science Perspective on the Role of Student Motivation in Learning and Teaching Contexts. Journal of Educational Psychology, 95(4) 667-686

[11] Goodin H., Stein D. (2009) The Use of Deliberative Discussion to Enhance the Critical Thinking Abilities of Nursing Students. The Berkeley Electronic Press, $5(1) 5$

[12] Goodin, H.J. Stein, D. (2008) Deliberative discussion as an innovative teaching strategy. Journal of Nursing Education, 47(6), 272-274.

[13] Kivinen, K. (2002) Assessing motivation and the use of learning strategies by secondary school students in three international schools. Academic dissertation, University of Tampere, Tampere.

[14] Leung, M., Chan, K. (2002) Gender and elective differences in the Motivated Strategies for Learning Questionnaire of pre-service teacher education students in Hong Kong. Hong Kong Institute of Education. Hong Kong. In Somtsewu N. The applicability of the motivated strategies for learning questionnaire (MSLQ) for South Africa. Master Thesis, Faculty of Health Sciences, Nelson Mandela Metropolitan University. 2008; 8-32

[15] Mello B. (2010) Using Discussion in the Classroom. available http://dev.natcom.org/uploadedFiles/Teaching a nd Learning/Virtual Faculty Lounge/In the Clas sroom/PDF-InTheClassroom-Using Discussion.pdf retrieved at March 2012.

[16] Melrose S. (2004) What Works? A Personal Account of Clinical Teaching Strategies in Nursing. Education for Health, 17(2):236 - 239

[17] Nilsson K, Stomberg M. (2008) Nursing students' motivation toward their studies - a survey study. BMC Nursing. available at http:// 
http://www.biomedcentral.com/14726955/7/6\#bm retrieved at march 2012

[18] Oermann, M. (2004) Using active learning in lecture: Best of both worlds. International Journal of Nursing Scholarship, 1(1), 1-9.

[19] Ormrod J. (1999) Human learning. 3rd ed. Upper Saddle River, NJ: Prentice-Hall, available at: http://edpsych.edb.utexas.edu/curriculum/dom ains/domain5.php retrieved at February 2012

[20] O'Shea E. (2003) Self-directed learning in nurse education: a review of the literature. Journal of Advanced Nursing, 43(1): 62-70

[21] Pintrich, P. R. (2003) A Motivational Science Perspective on the Role of Student Motivation in Learning and Teaching Contexts. Journal of Educational Psychology, 95( 4) 667-686

[22] Pintrich, P. R., Smith, D. A., Garcia, T., McKeachie, W. J. ( 1991) A manual for the use of the Motivated for Learning Strategies Questionnaire (MSLQ). University of Michigan, National Center for Research to Improve Postsecondary Teaching and Learning, 39.

[23] Ryan RM, Deci EL. Intrinsic and Extrinsic Motivations: Classic Definitions and New Directions. Academic Press, 2000; 25, 54-67

[24] Ryan RM, Deci EL. (2000) Self-Determination Theory and the Facilitation of Intrinsic Motivation, Social Development, and Well-Being. American Psychologist, 55(1):68-78.
[25] Skinner, F. (1953) Science and Human Behavior. New York: Free Press, 59-80

[26] Somtsewu N. (2008) The applicability of the motivated strategies for learning questionnaire (MSLQ) for South Africa. Master Thesis, Faculty of Health Sciences, Nelson Mandela Metropolitan University. 8-32

[27] Svinicki M. (2003) New Directions in Learning and Motivation. EBSCO Publishing available at http://www.ibe.unesco.org/fileadmin/user upl oad/archive/publications/EducationalPracticesS eriesPdf/prac10e.pdf retrieved at February 2012

[28] Svinicki, M. (2005) Student Goal Orientation, Motivation, and Learning. Center for Faculty Evaluation and Development in Higher Education, no. 41.

[29] Thornhill SK, Wafer MS. (1997) Clinical process learning to improve critical thinking. Nursing Connection, 10(3): 51-59.

[30] Wernke s., Wagener U., Anschuetz A., Moschner B.(2011) Assessing Cognitive and Metacognitive Learning Strategies in School Children: Construct Validity and Arising Questions. The International Journal of Research and Review, 6(2) 19-38

[31] YU Lin-ping. (2009) Upon the Application of Deliberative Method in Teaching Ideology, Ethics and Basic Law. Journal of Ningbo University, Educational Science Edition, 2009; (2) : 34-35. 